\title{
International Members
}

$\mathrm{T}$

his list recognizes the countries and territories of APSA's international members. As of March 2021, APSA had 1,921 international members from 95 countries, with approximately $20 \%$ of international members based in non-OECD countries. Thank you for your continued support of the association.

Algeria, 4

Argentina, 9

Armenia, 2

Australia, 47

Austria, 13

Bangladesh, 1

Belgium, 21

Benin, 1

Bosnia and Herzegovina, 1

Brazil, 39

Bulgaria, 1

Cambodia, 1

Cameroon, 4

Canada, 304

Chile, 13

China, 40

Colombia, 9

Cyprus, 3

Czech Republic, 7

Democratic Republic of the Congo, 1

Denmark, 26

Dominican Republic, 3

Ecuador, 2

Egypt, 9

Estonia, 5

Ethiopia, 2

Finland, 7

France, 30

Georgia, 2

Germany, 149

Ghana, 2

Greece, 3

Greenland, 1

Guam, 1
Poland 14

Portugal, 3

Qatar, 9

Romania, 2

Russia, 11

Saudi Arabia, 3

Senegal, 1

Serbia, 1

Singapore, 30

South Africa, 11

South Korea, 34

Spain, 26

Sudan, 3

Sweden, 39

Italy, 53

Jamaica, 1

Japan, 170

Jordan, 2

Kenya, 5

Kuwait, 3

Latvia, 3

Lebanon, 6

Liberia, 1

Lithuania, 1

Luxembourg, 1

Macao, 1

Macedonia, 1

Malaysia, 10

Mauritius, 2

Mexico, 39

Morocco, 13

Nepal, 1

Netherlands, 40

New Zealand, 7

Nigeria, 10

Norway, 31

Pakistan, 1

Panama, 1

Peru, 3

Philippines, 3

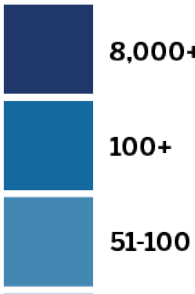

26-50

$11-25$

$1-10$

0
Switzerland, 54

Taiwan, 26

Tanzania, 2

Thailand, 5

Tunisia, 6

Turkey, 32

Ukraine, 1

United Arab Emirates, 11

United Kingdom, 297

United States, 8,081

Uruguay, 8

Vietnam, 1

Zimbabwe, 1 .

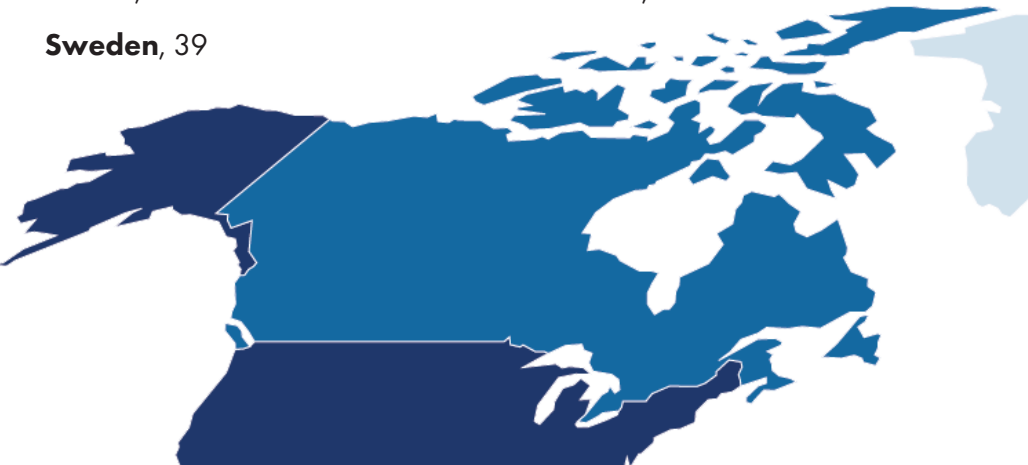




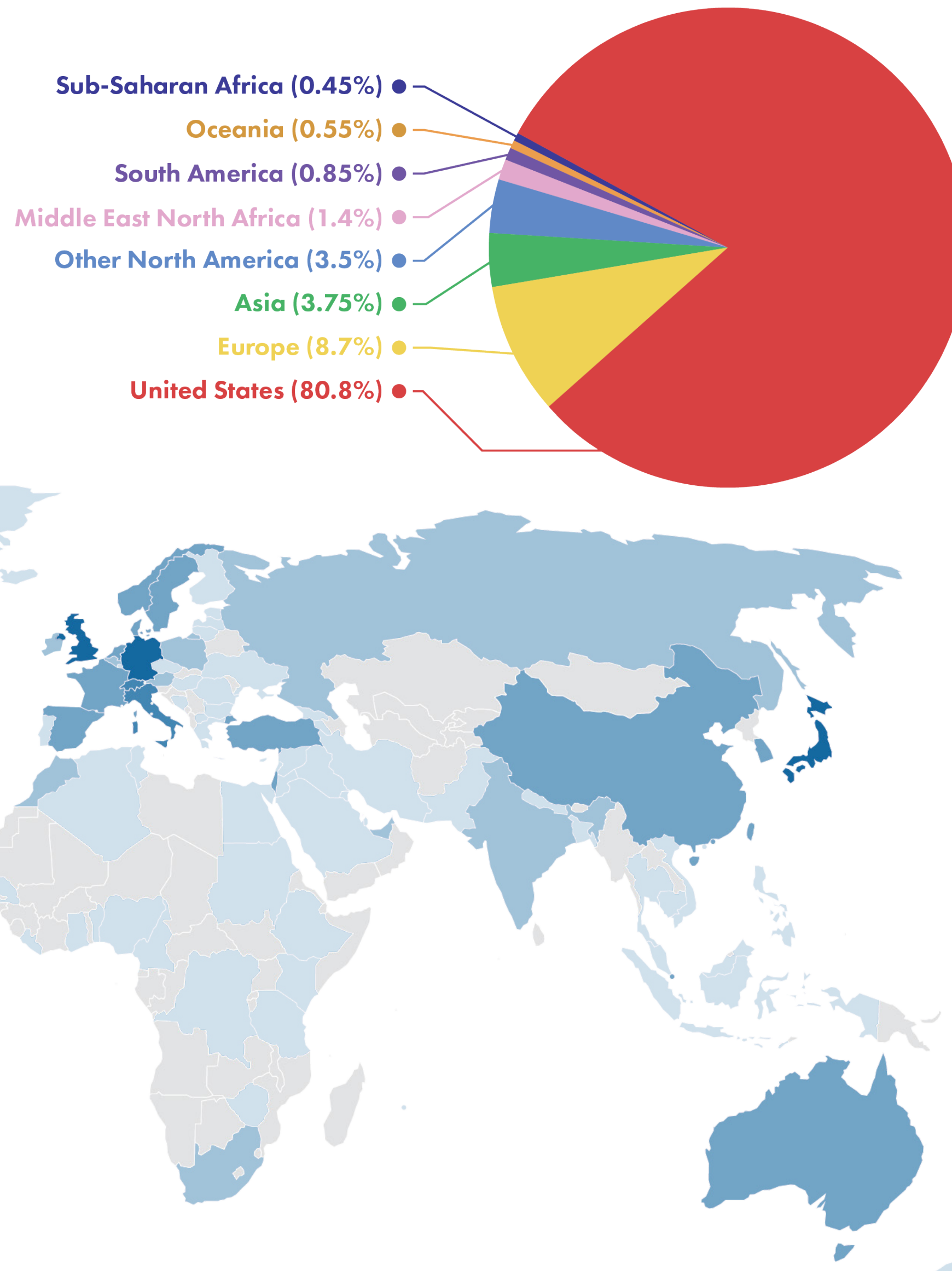

